\title{
Frequency of Mental Disturbances in HTLV-1 Patients in the State of Bahia, Brazil
}

\author{
André Gordilho Joaquim de Carvalho ${ }^{1}$, Ana Verena Galvão-Phileto ${ }^{1}$, Nana Santos Lima ${ }^{1}$, Rogério Santos de Jesus ${ }^{2}$, Bernardo \\ Galvão-Castro ${ }^{1,3}$ and Manuela Garcia Lima ${ }^{1}$ \\ ${ }^{1}$ Centro Integrativo e Multidisciplinar de HTLV e Hepatites Virais, Escola Bahiana de Medicina e Saúde Pública, Salvador, Bahia; ${ }^{2}$ Sanatório \\ São Paulo; ${ }^{3}$ Laboratório Avançado de Saude Pública, Centro de Pesquisas Gonçalo Moniz, Fundação Oswaldo Cruz; Salvador, Bahia, Brazil
}

\begin{abstract}
Viral infections and chronic diseases have been associated with psychiatric disorders. Among these, increased depression has been reported in HTLV-1 patients. However, no studies on the prevalence of other mental disturbances have been carried out in these patients. Salvador is the city with the highest rate of infection with HTLV-1 in Brazil and it is estimated that approximately 40,000 inhabitants are infected. In our cross sectional study, we examined the frequency of mental disturbances in 50 HTLV-1 seropositive patients followed at the Centro Integrativo e Multidisciplinar de HTLV e Hepatites Virais (CHTLV) of the Escola Bahiana de Medicina e Saude Pública (EBMSP) in Salvador from January to November 2007. We used a questionnaire to collect clinical-epidemiologic data and the Mini International Neuropsychiatric Interview Brazilian Version 5.0.0 (M.I.N.I.) to evaluate the psychiatric disorders. The Statistical Package for Social Sciences (SPSS) was used for the analyses. Twenty-one (42\%) HTLV-1 patients had a psychiatric co-morbidity; $17(34 \%)$ had mood disorders, $11(22 \%)$ were anxious and one (2\%) was an alcoholic. We found a high frequency of mental disturbances among HTLV-1 infected individuals, suggesting a possible association of this infection with psychiatric diseases. Key-Words: HTLV, Mental disturbances.
\end{abstract}

Human T-cell lymphotropic virus type 1 (HTLV-1), first isolated in 1980, is associated with leukemia/lymphoma of adult T cells (ATLL), with myelopathy/ tropical spastic paraparesis (HAM/TSP) and with other clinical manifestations, such as uveitis, arthritis, infective dermatitis and polymyositis [1-8]. HTLV-1 infection is endemic in Brazil where it has a prevalence varying from $0.4 \%$ to $1.8 \%$ [9] according to the geographic region [10]. Salvador is the city with the highest prevalence of this infection in the country and it is estimated that 40,000 inhabitants are infected [11].

Few studies have linked HTLV-1 with depression [12], however, there is no information about how the virus affects other types of mental disturbances. As mental disturbances are frequent among HIV patients [13-16] and among patients with chronic diseases [17-22] it is possible that HTLV patients might be more prone to mental disturbance. Our objective was to estimate the frequency of mental disturbances in HTLV1 patients, with and without associated clinical symptoms.

We carried out a cross sectional study from January to November 2007. Fifty HTLV-1 positive patients (ELISA \& Western Blot) from Salvador and other cities in the state of Bahia, of both genders, aged more than 18, with or without any manifestation of the disease, registered at CHTLV/EBMSP, were interviewed sequentially from January to November 2007.

We used a standardized questionnaire to collect epidemiological clinical data and the Mini International Neuropsychiatric Interview Brazilian Version 5.0 (M.I.N.I.) to evaluate psychiatric disturbances. This questionnaire consists Received on 9 August 2008; revised 3 December 2008.

Address for correspondence: Dr. André Gordilho Joaquim de Carvalho. Av Princesa Isabel 157/1002. Zip code: 40130-030 Salvador, Bahia, Brazil. Phones: (55) 71-32644847; 71-21092608; 71-88944847. Email: andregordilho@atarde.com.br.

The Brazilian Journal of Infectious Diseases

2009;13(1):5-8. (C) 2009 by The Brazilian Journal of Infectious Diseases and Contexto Publishing. All rights reserved. of a standardized diagnostic interview that was validated in more than 30 languages including Portuguese. This questionnaire includes the main mental problems of the group I of the fourth edition of the Diagnostic and Statistical Manual of Mental Disorders (DSM IV) (American Psychiatric Association, 1994) and the International Classification of Diseases (CID-10) (OMS, 1992) [23].

The sample size was calculated considering $30 \%$ as the estimated prevalence of the event, with a desired precision of $15 \%$, based on published information for psychiatric disturbances for the general population. Using a power of $80 \%$ and an alpha error of $5 \%$, we calculated a sample size of 44 patients, which was increased by $10 \%$ to compensate for possible losses, giving a final sample size of 50 patients. The calculation of the sample size was made using the program Epitable of the software EpiInfo 2000.

The statistical analysis was initially descriptive, calculating the mean \pm standard deviation for all of the continuous variables and the percentages in the various categories. Comparisons between proportions were made using the chi square test $\left(\chi^{2}\right)$ and the Exact Fisher test. The program SPSS (Statistical Package for Social Sciences) was used to make the statistical calculations, which were considered significant when $\mathrm{p}<0.05$.

We recorded the sociodemographic characteristics of the sample: 34 patients (68\%) were females and $16(32 \%)$ were males, with a mean age of $46.9 \pm 13.0$ years (median 46 years), with no significant difference between sexes. Most $(n=30 /$ $60 \%$ ) were not married, and were not white skinned (44/88\%); half of the patients, $26(52 \%)$ had little schooling and 27 (54\%) were from the countryside.

The analysis of the variables associated with infection with HTLV indicated that $32(64 \%)$ patients had been infected for more than two years (the mean time was $52.0 \pm 46.6$ months, with a median of 36 months); 26 (52\%) presented associated clinical manifestations, and 22 (44\%) routinely used medication. 
Table 1. Frequency of mental disorders in $50 \mathrm{HTLV}-1$ patients attended at the Centro Integrativo e Multidisciplinar de HTLV e Hepatites Virais da Escola Bahiana de Medicina e Saude Pública. Corresponding percentages are given in parentheses.

\begin{tabular}{lccc}
\hline Diagnosis & All patients (n=50) & Symptomatic (n=26) & Asymptomatic (n=24) \\
\hline Mood disorders & $17(34 \%)$ & $10(39 \%)$ & $7(29 \%)$ \\
Depression & $15(30 \%)$ & $9(35 \%)$ & $6(25 \%)$ \\
Manic & $2(4 \%)$ & $2(7.7 \%)$ & $0(0 \%)$ \\
Anxiety disorder & $11(22 \%)$ & $6(23 \%)$ & $5(21 \%)$ \\
General anxiety & $7(14 \%)$ & $4(15 \%)$ & $3(13 \%)$ \\
Agoraphobia & $6(12 \%)$ & $3(12 \%)$ & $3(13 \%)$ \\
Panic & $5(10 \%)$ & $2(7.7 \%)$ & $3(13 \%)$ \\
Social phobia & $2(4 \%)$ & $0(0 \%)$ & $2(8.3 \%)$ \\
OC & $2(4 \%)$ & $0(0 \%)$ & $2(8.3 \%)$ \\
PTS & $1(2 \%)$ & $0(0 \%)$ & $1(4.2 \%)$ \\
\hline
\end{tabular}

$\mathrm{OC}=$ obsessive compulsive disorder; PTS $=$ post-traumatic stress.

Based on MINI, 21 patients (42\%) had some kind of mental disturbance. Seventeen patients (34\%) had mood disorders (nine with mood disorders alone and eight associated with anxiety disorders), 11 (22\%) patients had anxiety disorders (three with anxiety disorder alone and eight associated with mood disorder) and one (2\%) patient was alcoholic. Among the patients with mood disorders, 15 (30\%) were depressive and two (4\%) were manic. Among the patients with anxiety, seven $(14 \%)$ had general anxiety, six $(12 \%)$ had agoraphobia, five (10\%) had panic disorder, two (4\%) had social phobia, two (4\%) had obsessive-compulsive disorder and one (2\%) had post-traumatic stress disorder (Table 1). Among the individuals with mood changes, we included patients with concomitant anxiety disorder, and vice-versa. A higher frequency of mental disorder was found in females, $17 / 34(50 \%)$ against $25 \%$ in males, in individuals up to 46 years old 14/26 (53.8\%), in patients from the capital 12/23 $(52.2 \%)$ and among non-white skinned individuals 20/44 $(45.5 \%)$.

Comparing the appearance of mental disorder according to the evolution of the disease in our group, we found a higher frequency of mental disorder in the symptomatic subgroup $(46.2 \%$ versus $37.5 \%$; relative frequency $=1.23 ; 95 \%$ CI 0.911 .52 ; $\mathrm{p}=0.58$ ), but this difference was not significant. There was a

Figure 1. Frequency of mental disorders associated with previous use of antidepressants. ADT $=$ antidepressant.

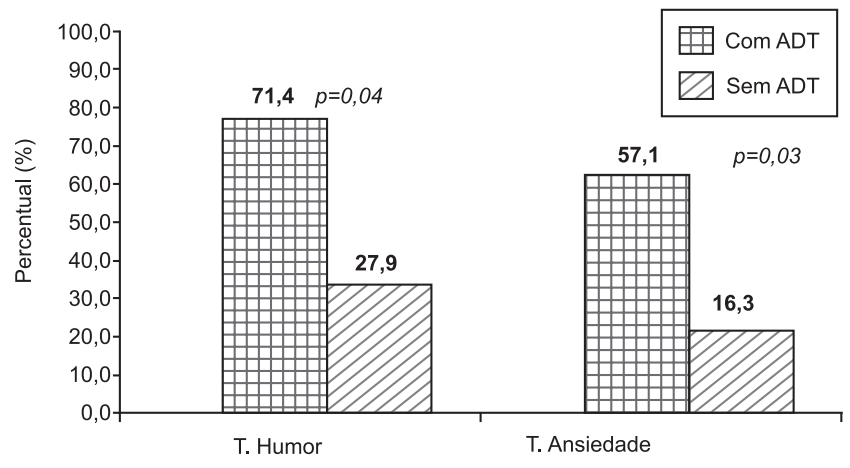

higher frequency of mental disturbance in female patients, but the difference was not significant; there was a greater frequency of mood disorders, followed by anxiety disorders, particularly in symptomatic individuals.

Among the patients, seven (14\%) were being medicated with amitriptyline at low doses $(25 \mathrm{mg})$. When we compared the rates of mental disorder, we observed that this subgroup had a greater frequency of mental disorder $(71.4 \%$ versus $37.2 \% ; \mathrm{p}=0.09$ ) as well as specific disorders (mood disorders 71.4 versus $27.9 ; \mathrm{p}=0.04$ ) and (anxiety disorders 57.1 versus $16.3 ; \mathrm{p}=0.03$, Figure 1 ).

With the exception of human immunodeficiency virus (HIV) and hepatitis C virus (HCV), there is very little scientific evidence for a link between mental disorders and virus diseases [12]. To date, few studies have evaluated depression in HTLV-1 patients. Other studies have described anxiety and depression, but they have not investigated the association of these syndromes with HTLV using an adequate methodology because they used evaluation ratings of the symptoms, instead of standardized diagnostic instruments or they looked for this information in previous notes in the medical files. We did not find studies that looked for other psychiatric diseases in this group of patients. In this study, we used MINI, which consists of a short standardized diagnostic interview, compatible with the diagnostic criteria of DSM-IV and CID-10, which identifies current and past psychiatric disorders [23, 24].

We found a high frequency of mental disorders in HTLV1 patients. The overall frequency of psychiatric disorders $(42 \%)$ was similar to the results of an epidemiological study of psychiatric morbidity, which indicated a prevalence of $48 \%$ in the general population [25]. Community based studies on mental disorders in Brazil have estimated the prevalence to be from 30 to $50 \%$, similar to that we found in our study on HTLV1 patients $[26,27]$.

However, considering more recent studies conducted by WHO, the prevalence of mental disorders in the general population is lower than what we found in HTLV1 patients $[28,29)]$. 
The frequencies of mood (18\%) and anxiety disorders (22\%) that we found are similar to the prevalences of $19.3 \%$ and $24.8 \%$, respectively, reported in an epidemiological study of the general population [25]. Mood disorders (including mood and anxiety disorders) were more frequent in our patient group (34\%) than in the general population. The rates of alcohol abuse and alcoholism (4\%) were significantly lower than in the general population (24.8\%). This difference could be either due to cultural differences or because these patients often take medicine that should not be taken with alcoholic beverages.

The prevalence of anxiety disorders was different from that found in a study of the general population in three metropolitan areas of Brazil in which it varied from $10 \%$ to $18 \%$ [26]. In a population study conducted in Brazil, the most prevalent disorder was nicotine dependence $(25 \%)$, not examined in our study. However, alcohol abuse was found in $5.5 \%$ in that study, similar to what we found (4\%) [27].

Although mood and anxiety disorders are more common in women, and abuse of or dependence on alcohol and other substances more common in men, the overall frequency of mental disorders in the general population does not differ between genders [25]. Seroprevalence of HTLV-1 is high among women [11]. We noted a higher number of women infected than men, and a two fold higher frequency of mental disorders in this group ( $50 \%$ of the women, compared to $25 \%$ of the men). The frequency of mood and anxiety disorders was also higher in women, though the difference was not significant $(\mathrm{p}=0.13)$.

A study carried out in Salvador showed that the rate of HTLV-1 infection increases with age and is higher among patients with little schooling. [11]. We did not observe these trends nor an association of mental disorders with increasing age among HTLV-1 patients.

The frequency of mental disorders that we found (42\%) was similar to those observed in studies carried out into patients with chronic diseases (31\% to $66 \%$ ) [20], and to those reported for HIV patients (45\%) [15]. We have no information about possible mechanisms or if HTLV-1 might cause mental disorders in infected patients. Nevertheless, we suggest that these disorders could be a consequence of the chronic infection caused by HTLV, of associated incapacitating clinical problems, and of possible psychopathological alterations directly associated with infection.

Among the variables associated with HTLV-1, there was a higher frequency of mental disorders in the symptomatic patients ( $46 \%$ versus $37.5 \%$ ), and in the patients on medication (54.5\% versus $32.1 \%$ ). We also observed that patients who had previously used low doses of antidepressants had higher rates of mood disorders $(71.4 \%$ versus $27.9 \%$; $\mathrm{p}=0.04)$ and of anxiety disorders $(57.1 \%$ versus $16.3 \%$; $\mathrm{p}=0.03)$.

Although not all differences were significant, we believe there is a greater likelihood of HTLV-1 patients developing mental disorders due to the severe impairment caused by this incapacitating disease.

\section{References}

1. Cruz B.A., Catalan-Soares B., Proietti F. Higher prevalence of fibromyalgia in patients infected with human $\mathrm{T}$ cell lymphotropic virus type I. J Rheumatol 2006 Nov;33(11):2300-3.

2. Gessain A., Barin F., Vernant J.C., et al. Antibodies to human Tlymphotropic virus type-I in patients with tropical spastic paraparesis. Lancet 1985 Aug 24;2(8452):407-10.

3. Lagrenade L., Hanchard B., Fletcher V., et al. Infective dermatitis of Jamaican children: a marker for HTLV-1 infection. Lancet 1990 Dec 1;336(8727):1345-7.

4. Mochizuki M., Watanabe T., Yamaguchi K., et al. Uveitis associated with human T-cell lymphotropic virus type I. Am J Ophthalmol 1992 Aug 15;114(2):123-9.

5. Nishioka K. HTLV-1 arthropathy and Sjogren syndrome. J.Acquir.Immune. Defic Syndr Hum Retrovirol 1996;13 Suppl 1:S57-S62.

6. Osame M., Usuku K., Izumo S., et al. HTLV-1 associated myelopathy, a new clinical entity. Lancet 1986 May 3;1(8488):1031-2.

7. Poiesz B.J., Ruscetti F.W., Gazdar A.F., et al. Detection and isolation of type $\mathrm{C}$ retrovirus particles from fresh and cultured lymphocytes of a patient with cutaneous T-cell lymphoma. Proc Natl Acad Sci U.S.A 1980 Dec;77(12):7415-9.

8. Yoshida M., Miyoshi I., Hinuma Y. Isolation and characterization of retrovirus from cell lines of human adult T-cell leukemia and its implication in the disease. Proc Natl Acad Sci U.S.A 1982 Mar;79(6):2031-5.

9. Silva F.A., Méis E., Dobbins J.A., Oliveira M.S.P. Leucemialinfoma de células $\mathrm{T}$ do adulto no Brasil: epidemiologia, tratamento e aspéctos controversos. Rev Bras Câncer 2002;37[4]:470-6.

10. Galvao-Castro B., Loures L., Rodriques L.G., et al. Distribution of human T-lymphotropic virus type I among blood donors: a nationwide Brazilian study. Transfusion 1997 Feb;37(2):242-3.

11. Dourado I., Alcantara L.C., Barreto M.L., et al. HTLV-1 in the general population of Salvador, Brazil: a city with African ethnic and sociodemographic characteristics. J Acquir Immune Defic Syndr 2003 Dec 15;34(5):527-31.

12. Stumpf B.P., Rocha F.L., Carneiro-Proietti A.B. Infecções virais e depressão. J Bras Psiquiatria 2006;55[2]:132-41.

13. Arendt G., Haslinger B.A. Psychiatric diseases and HIV infection. These patients are dually stigmatized. MMW Fortschr Med 2003 Apr 28;145 Spec No 1:70-2.

14. Arendt G. Affective disorders in patients with HIV infection: impact of antiretroviral therapy. CNS. Drugs 2006;20(6):507-18.

15. Bellini M., Bruschi C., Babini P., et al. Diagnosis of major depression in HIV-infected patients. Minerva Psichiatr 1994 Sep;35(3):129-38.

16. Penzak S.R., Reddy Y.S., Grimsley S.R. Depression in patients with HIV infection. Am J Health Syst Pharm 2000 Feb 15;57(4):376-86.

17. Bankier B., Januzzi J.L., Littman A.B. The high prevalence of multiple psychiatric disorders in stable outpatients with coronary heart disease. Psychosom Med 2004 Sep;66(5):645-50.

18. Buskila D., Cohen H. Comorbidity of fibromyalgia and psychiatric disorders. Curr Pain Headache Rep 2007 Oct;11(5):333-8.

19. Fietta P., Fietta P., Manganelli P. Fibromyalgia and psychiatric disorders. Acta Biomed 2007 Aug;78(2):88-95.

20. Fullerton C., Florenzano R., Acuna J. Comorbidity of chronic diseases and psychiatric disorders among patients attending public primary care. Rev Med Chil 2000 Jul;128(7):729-34.

21. Placidi G.P., Boldrini M., Patronelli A., et al. Prevalence of psychiatric disorders in thyroid diseased patients. Neuropsychobiology 1998 Nov;38(4):222-5.

22. Twillman R.K. Mental disorders in chronic pain patients. J Pain Palliat Care Pharmacother 2007;21(4):13-9. 
23. Amorim P. Mini International Neuropsychiatric Interview (MINI): validação de entrevista breve para diagnóstico de transtornos mentais. Rev Bras Psiquiatria 2000;22:106-15.

24. Sheehan D.V., Lecrubier Y., Sheehan K.H., et al. The MiniInternational Neuropsychiatric Interview (M.I.N.I.): the development and validation of a structured diagnostic psychiatric interview for DSM-IV and ICD-10. J Clin Psychiatry 1998;59 Suppl 20:22-33.

25. Kessler R.C., McGonagle K.A., Zhao S., et al. Lifetime and 12month prevalence of DSM-III-R psychiatric disorders in the United States. Results from the National Comorbidity Survey. Arch Gen Psychiatry 1994 Jan;51(1):8-19.
26. Almeida-Filho N., Mari J.J., Coutinho E., et al. Brazilian multicentric study of psychiatric morbidity. Methodological features and prevalence estimates. Br J Psychiatry 1997 Dec;171:524-9.

27. Andrade L., Walters E.E., Gentil V., Laurenti R. Prevalence of ICD-10 mental disorders in a catchment area in the city of Sao Paulo, Brazil. Soc Psychiatry Psychiatr Epidemiol 2002 Jul;37(7):316-25.

28. Regier D.A., Boyd J.H., Burke J.D., Jr., et al. One-month prevalence of mental disorders in the United States. Based on five Epidemiologic Catchment Area sites. Arch Gen Psychiatry 1988 Nov;45(11):977-86.

29. Organização Mundial de Saúde. Relatório Sobre a Saúde no Mundo 2001. Saúde Mental: Nova Concepção, Nova Esperança. 48-51. 2001. 